\title{
On the Application of TBLT Focus on Form in College English Teaching
}

\author{
Yin Xiaofang \\ Yuanpei College of Shaoxing University \\ Shaoxing, China \\ isabella08@sina.com.cn
}

\begin{abstract}
TBLT Focus on Form can contribute much to developing the students' ability to use the target language effectively, correctly and appropriately and help the students to form positive affection in their language learning. Thus it is an more effective teaching approach.
\end{abstract}

Keywords-Task-based language teaching (TBLT); focus on form;experimental research

\section{I.INTRODUCTION}

In China, English is taught as a foreign language rather than a second language. It is traditionally learnt as a school subject of knowledge in China. Therefore, it is mainly considered as a foreign language. So we don't have the ideal conditions that a native speaker possesses all the time.

We can say that language forms should be emphasized in Chinese background and it must be strengthened to develop students' grammatical competence as well as to develop their communicative competence so that the correction and decency of the expression of the students can be guaranteed.

Task-based Language Teaching Focus on Form emphasizes the communicative function of language by asking learners to fulfill varied tasks which are imitations of real life language functions. It designs different tasks according to the learner' proficiency or their supposed

response, which may make learners aware of the learning process, and the special links that need to be strengthened.

\section{LITERATURE REVIEW}

TBLT is based on the theory of activities teaching. It is a practice pattern in language teaching field. Nunan (1991)considers TBLT as an emphasis on learning to communicate through interaction in the target language, the introduction of authentic texts into the learning situation, the provision of opportunities for learners to focus not only on language but also on the learning process, an enhancement of the learner's own personal experiences as important contributing elements to classroom learning and an attempt to link classroom language learning with language activation outside the classroom.

There are three types of TBLT: TBLT Focus on forms, TBLT Focus on meaning and TBLT Focus on form. TBLT Focus on forms, or structure-oriented TBLT, concentrates much on forms, while TBLT Focus-on-meaning, or communication-oriented TBLT focuses much on meaning at the expense of forms. TBLT Focus on form, or intermediate TBLT, is the balance between forms and meaning. It emphasizes different aspects of language performance, particularly accuracy, fluency, and complexity.

TBLT Focus on forms is advocated that teaching activities should be designed to constrain language use in such a way that specific structures will be used. When a student needs to communicate through the foreign language, he must search consciously for words and expressions needed. On the contrary, TBLT Focus-onmeaning puts more emphasis on communicating with each other without mention of any language forms. The researchers argue that students themselves can drive forward their language development. They advocate abandoning purely forms-focused instruction in favor of an equally single-minded focus-on-meaning. Skehan (1998) proposes TBLT Focus on form, or intermediate TBLT, which emphasize different aspects of language performance, particularly accuracy, fluency, and complexity. The introduction of elements while performing the tasks will promote attention to language forms (Rod Ellis 1997). The instruction built around a focus on form result in faster learning and higher levels of proficiency. So the TBLT Focus on Form is comparatively a most practical and effective teaching method for the TEFL in China.

TBLT Focus on Form emphasizes focusing on forms and meaning at the same time, and attentional manipulation is most important. Skehan (1988) argues that what is needed is to consider approaches which, in the context of meaningful communication, draw learners' attention to language forms naturally rather than artificially. He elaborates on the idea with the processingbased analyses of tasks as departure. That is, more demanding tasks consume more attentional resources simply for task transaction, with the result that less attention is available for TBLT. Through manipulating cognitive demands of tasks, desirable aspects of language performance can be predisposed so as to achieve a balance between the three goals: fluency, accuracy, and complexity. Thus, tasks can be selected effectively to maximize the chances of a focus on form through attentional manipulation. This means a balance is kept. 


\section{IMPLEMENTATION OF TBLT FOCUS ON FORM IN ENGLISH CLASSES}

TBLT Focus on Form asserts that languagelearning depends on students' being involved in real communication in which they use language in a meaningful way. It crucially insists that acquisition needs to be supported by instruction that ensures a certain attention to linguistic form that initial fluency work should lead gradually to accuracy-focused activities. So it can meet the students' learning process and their individual difference. Meanwhile it can also keep a balance between accuracy and fluency. Through practice and research, some advocators of TBTL have set up a series of teaching frameworks and have proved to be successful and satisfactory, such as, Jane Will's framework for TBLT, which has three stages in the implementation of the tasks---pre-task activities, task cycle and language focus activities(Willis, 1996:38).

With experiences of teaching and theory study, I practice the following framework of focus on form taskbased language teaching on the basis of Willis' model. There are six stages in it.

\section{A. Lead-in (introduction to the task; inspire students' interests)}

In this stage, the teacher introduces students some related information about the task to inspire their curiosity, learning motivation and interests in the way of pictures, record and video, etc. Learning interest is the important element of learning motivation, and is most active element of study positivity. So the teacher should focus on the inspiration and cultivation of the students' learning interests in the lead-in stage.

\section{$B$ Pre-task (input of the related information about the topic and task)}

In the pre-task stage, students are familiar with the topic. The teacher explores the topic with the class, highlights useful words and phrases and helps students prepare for the task. Meanwhile students are inspired to the task-related background knowledge and are introduced the detailed steps to implement the task.

C. Task cycle (negotiation of meaning or content; planning the task; oral presentation and justification)

The aim of this stage is to make students understand and consolidate new knowledge in the process of students' independent study. There are three steps in the task cycle: 1) students are required to work in small groups to cooperate and negotiate on the meaning or content or discuss in response to reading a text or listening to a record. Students focus on meaning. 2) prepare to report. Students here prepare to report to the classmates and the teacher, orally or in writing. According to their own group work result, they use their own language to prepare for a presentation about how they dealt with the problem, what they discovered or concluded, etc. 3) oral presentation. Some groups present their report to the whole class or exchange and compare written reports. Other students listen to them. The teacher at that time chairs the session, commenting on reports and encouraging students if needed.

D. Language form focus (introduction of language forms based on learners-initiated meanings; students' negotiation of form together and practice)

The stage consists of two parts. First, the teacher sets language-focused tasks based on the texts students have read or on transcripts of what they have heard. Then, the students negotiate language forms together and practice new words, phrases or patterns that occur in the data analyzed. The idea is not that students will gain immediate command of these features but that by noticing them, they will recognize them when they meet again in other texts.

E Reflection (students' reflection about their performance during the task; development of students' interlanguage system )

It is the stage of analyzing and evaluating. In the stage students reflect their performance during the task. The aim is to help students to improve their accuracy of the language forms, improve their interlanguage system and develop their abilities. Teacher can play the tape or video of the familiar task. Then students know very clearly how to use the target language.

\section{F. Consolidation (homework)}

It is the stage of extending the task. The teacher arranges some oral or written homework related to the classroom task to consolidate the achievement or to reinforce the knowledge in class.

The framework starts with creating an actual need to use language to perform the task. Then the next stages are served to finish the task. Language form focus is supported by consciousness-raising and analysis. And stages 5and 6 are used to give students impression of what they have learned.

\section{AN EXPERIMENTAL STUDY}

There are three major factors relevant to the research design. They are subjects, instruments, and the procedure.

Subjects: first-year non-English majors from two classes in Shaoxing College of Arts and Science.

Instruments: two tests and two questionnaires.

Teaching materials: College English, published by Shanghai Foreign Language Education Press. The teaching experiment lasted eight weeks, five periods for every week.

Procedure: The writer conducted an eight-week experiment with five periods every week. The writer uses the traditional approach in class one, while in class two, as named experimental class, the writer uses TBLT Focus on Form in class. At the end of the experiment, the subjects are asked to take another test to see whether the task-based 
approach will be more effective than the traditional approach.

\section{CONCLUSION}

Firstly, TBLT Focus on Form has a differential effect on College English learning compared with the traditional approach. It provides a better and more effective way to improve the students' skills and ability of studying English as a second language. Form-focus learning in class raises the consciousness of the learners on the target form. And students are provided opportunities to make output based on the input they have been exposed to after their consciousness is raised. They tend to process the input with more focused attention on how the forms are used to convey particular meanings. Thus, the channel linking the form and meaning is strengthened in this process, which is an important component of language accuracy.

Secondly, TBLT Focus on Form creates encouraging atmosphere in class that the students motivation, interests and confidence are much improved. But in class they often meet various difficulties, especially some linguistic problems in communicating with peers, which discourages students to communicate more.

Thirdly, it is very important to for the teachers to design proper tasks to the meet the needs of students. Before the class begins, teachers should do a need analysis of students. The analysis includes students' purposes to learn English, their interests, motivation, learning styles and so on.

Fourthly, TBLT Focus on Form sets higher demands for teachers. In order to have successful English classes, teachers do need not only the language proficiency but also the abilities of organization, management, regulation, communication, and evaluation, etc. Theoretical knowledge is really important as well as language knowledge. So teachers should be provided more chances to get further education.

\section{REFERENCES:}

[1]Nunan, D. Communicative tasks and the language curriculum [J]. TESOL Quarterly, 25(2):279-295,1991.

[2]Ellis Rod. Second Language Acquisition[M]. Oxford: Oxford University Press, 1997.

[3]Skehan, P. Task-based instruction[J]. Annual Review of Applied Linguistics, 1998, 18.

[4]Skehan, P. A cognitive Approach to Language Learning[M].Oxford University Press,1998.

[5]Willis, J. A framework for task-based learning[M]. London: Longman,1996.

[6]Fotos, S. Shifting the focus from forms to form in the EFL classroom[J]. ELT Journal, 52/4307-310,1998.

[7]Sheen, Ron. "Focus on form" and "focus on forms" [J].ELT Journal Volume 56/3 2002.7. 